\title{
Macrogol (polyethylene glycol) 4000 without electrolytes in the symptomatic treatment of chronic constipation: a profile of its
}

\section{use}

\section{Katherine A. Lyseng-Williamson ${ }^{1}$}

Published online: 15 June 2018

๑) Springer Nature 2018, corrected publication 2018

\begin{abstract}
Macrogol 4000, a biologically inert, non-absorbable osmotic laxative, is a highly effective and well-tolerated first-line option for the treatment of the symptoms of chronic idiopathic/functional constipation in children and adults. High-molecular-weight (HMW) macrogols \pm electrolytes have generally similar efficacy profiles; however, the taste of macrogol 4000 is generally preferred over that of macrogol 3350+electrolytes. Macrogol 4000 is more effective than lactulose in improving stool frequency and consistency, and is associated with less vomiting and flatulence. Comparisons with other osmotic and bulk-forming laxatives are limited, with macrogol 4000 being at least as, or more effective than, psyllium hydrocolloid and magnesium hydroxide in treating chronic constipation. Current clinical treatment guidelines recommend the use of HMW macrogols over the use of lactulose and bulk-forming laxative in the symptomatic treatment of constipation in children and adults.
\end{abstract}

Adis evaluation of macrogol $\mathbf{4 0 0 0}$ without electrolytes in the symptomatic treatment of chronic constipation

Biologically inert, non-absorbable osmotic laxative

Improves stool frequency and consistency, as well as other constipation-related outcomes, in children and adults

Responses to treatment are durable without dosage increases

Equally effective as HMW macrogols + electrolytes and more effective than lactulose

Very well-tolerated, with less vomiting and flatulence than lactulose

Not associated with clinically relevant electrolyte disturbances

May be taken by diabetics and patients on low-sodium diets

Taste preferred over that of HMW macrogols + electrolytes

Recommended as first-line symptomatic treatment in paediatric and adult treatment guidelines

Katherine A. Lyseng-Williamson

dtp@adis.com

1 Springer, Private Bag 65901, Mairangi Bay 0754, Auckland, New Zealand

\section{What is the rationale for using macrogol 4000 in constipation?}

Chronic constipation is a common problem in individuals of all ages [1-5], with functional constipation having a prevalence of $9.5 \%$ (95\% CI 7.1-12.1) in children [5], and chronic idiopathic constipation having a median prevalence of $12 \%$ (95\% CI 12-17) in adults [1]. Health-related quality of life (HR-QOL) is impaired in patients with chronic constipation $[6,7]$ Treatment of chronic idiopathic/functional constipation should include dietary and lifestyle changes (e.g. adequate fluid intake, increased dietary fibre, regular exercise and good bowel habits), and when these changes are insufficient, adjunctive treatment with a laxative, generally an osmotic or bulk-forming agent [4, 8-13].

Osmotic laxatives increase the volume of intestinal fluids to the stools, improving the progression of the stool in the colon, as well as improving defaecation [14]. Such agents include macrogols [inert, biologically inactive, non-absorbable polymers; also known as polyethylene glycols (PEGs)], poorly absorbed disaccharides (e.g. lactulose and lactitol, which are metabolized in the colon by bacterial flora) and poorly absorbed ions (e.g. magnesium hydroxide). Highmolecular-weight (HMW) macrogols (i.e. macrogol 3350 and $4000 \pm$ electrolytes) are indicated as first-line osmotic treatments for chronic constipation in children $[8,9,13]$ and adults [10-12], as well as being used for bowel cleansing 
prior to colonoscopy [14]. The length of the polymerization process determines the molecular weight of a macrogol, with the weighted average of the relatively narrow range of individual macrogol molecules providing the molecular weight of a given macrogol [14].

This article reviews the pharmacological, efficacy and tolerability profiles of macrogol 4000 without electrolytes. It is available as sachets for use in children aged $>6$ months and $<8$ years (4-g sachet) [15] and older children and adults (10-g sachet) [16].

\section{For whom is macrogol 4000 indicated?}

Macrogol 4000 is used for the symptomatic treatment of constipation in adults and children aged $\geq 6$ months $[15,16]$. It should be taken as a temporary treatment for constipation in addition to a healthy lifestyle and diet; in children, the maximum duration of treatment should be 3 months. Before initiation of treatment, an organic cause of constipation should be ruled out. The effects of macrogol 4000 become apparent within $24-48 \mathrm{~h}$ of administration $[15,16]$.

In many countries worldwide, macrogol 4000 powder for oral solution is available as 4- and 10-g sachets for use in children aged $\geq 6$ months and $<8$ years, and adults and children aged $\geq 8$ years, respectively (Table 1 ). In European Economic Area (EEA) member states, it is authorized as generic macrogol 4000, as well as under several tradenames, including Dulcobalance ${ }^{\circledR}$ (UK), Dulcolax M Balance ${ }^{\circledR}$ and Laxofalk $^{\circledR}$ (Germany), Forlax ${ }^{\circledR}$ (Austria, Belgium, Czech Republic, Estonia, France, Latvia, Lithuania, Luxemburg, Poland, Portugal, Slovakia and the Netherlands), Idrolax ${ }^{\circledR}$ (Ireland), Paxabel ${ }^{\circledR}$ (Italy) and Tanilas ${ }^{\circledR}$ (Greece). It is also available in many other countries, including, but not limited to, Algeria, Australia, Ukraine, Russia and Vietnam, as well as in countries in Africa.

Table 1 provides a summary of the use of macrogol 4000 as approved in the EEA member states $[15,16]$. Consult local information for further details.

\section{What are the pharmacological properties of macrogol 4000 ?}

\section{Pharmacodynamic profile}

Macrogol 4000, a mixture of long, linear non-absorbable and non-metabolizable ethylene glycol polymers with a mean molecular weight of $4000 \mathrm{Da}$, is an osmotic laxative $[15,17]$. Water molecules in the intestinal tract are bound to the polymer by hydrogen bonds, thereby increasing the volume of the stool and softening its consistency, and, ultimately, relieving constipation [15, 17]. Macrogol 4000 does not permeate the gut to an appreciable extent and, therefore, is not systemically absorbed. In animal studies, absorption of radio-labelled macrogol 4000 was small, with the absorbed macrogols consisting primarily of molecules with a molecular weight of $<4000$ [18], and with increased gut permeability being shown in animals with experimental colitis [19].

In pharmacological studies in healthy volunteers [20-24] and/or adult or paediatric patients with constipation [22, 25-29], the use of macrogol 4000 has been shown to:

- improve colonic transit and/or stool frequency [21-23, 25].

- improve faecal consistency and increase stool water output [24].

- have little effect on intestinal microbial composition $[26,28]$.

- be free of clinically relevant electrolyte disturbances (i.e. very small or no loss of sodium, potassium and chloride in the stool) $[20,23,27]$.

- not cause sustained elevations of ethylene glycol, diethylene glycol or triethylene glycol [29].

\section{Pharmacokinetic profile}

Although studies of the pharmacokinetics of macrogol 4000 are lacking, pharmacokinetic studies of macrogol 3350 have shown that orally administered HMW macrogols undergo minimal absorption, and are rapidly and almost completely excreted unchanged via the faeces (elimination half-life $\approx 4-6 \mathrm{~h}$, with $\approx 93 \%$ of a single dose excreted in the faeces) [30].

The use of macrogol 4000 could potentially have transient effects on the intestinal absorption of some drugs [31], particularly those with a narrow therapeutic index or short half-life (e.g. digoxin, anti-epileptics, coumarin anticoagulants and immunosuppressive agents). Decreased absorption could, in turn, lead to decreased efficacy. For example, in a crossover study in healthy volunteers, macrogol 4000 (20 g/day for 8 days) significantly $(p<0.05)$ decreased exposure to single-dose digoxin $0.5 \mathrm{mg}$ relative to digoxin alone; however, heart rate and AV conduction were not affected [31]. The gastrointestinal (GI) absorption of other drugs (some NSAIDs, anticoagulants and gastric antisecretory agents, as well as a hypoglycaemic sulfamide) was not affected by administration of macrogol 4000 in animal studies [15]. 
Table 1 Summary of the use of macrogol 4000 in the treatment of constipation in adults and children $[15,16]$

How should the 4-g sachets of macrogol 4000 be taken in children aged $\geq 6$ months and $<8$ years?

Before treatment initiation

Rule out an organic cause of constipation

Recommended dosage

Age 6 months to $<1$ year: one 4-g sachet daily

Age 1 to $<4$ years: one or two 4-g sachets $(4-8 \mathrm{~g})$ daily

Age 4 to $<8$ years: two to four $4-\mathrm{g}$ sachets $(8-16 \mathrm{~g})$ daily

Dosage adjustment

Adjust according to the expected clinical response

Timing of administration

One sachet: a single dose in the morning

More than one sachet/day: split between morning and evening doses

Duration of treatment

Should not exceed 3 months (lack of longer-term data); maintain treatment-induced restoration of bowel movements by lifestyle and dietary measures

How should the 10-g sachets of macrogol 4000 be taken in adults and children aged $\geq 8$ years?

Before treatment initiation

Rule out an organic cause of constipation

Dosage

One 10 -g sachet daily, increasing to two 10 -g sachets $(20 \mathrm{~g})$ per day

Dosage adjustment

May range from one sachet every other day (especially in children) up to a maximum of two sachets per day according to the clinical response obtained

Timing of administration

Duration of treatment in children aged $\geq 8$ years

Preferably as a single dose in the morning

Should not exceed 3 months (lack of longer-term data); maintain treatment-induced restoration of bowel movements by lifestyle and dietary measures

How should the 4- and 10-g sachets of macrogol 4000 be prepared?

Dissolve contents of the sachet(s) in a glass of water $(\geq 50 \mathrm{~mL})$ and drink immediately

What are the contraindications to the use of macrogol 4000 ?

Hypersensitivity to macrogol (polyethylene glycol) or any of the other ingredients

Existing severe inflammatory bowel disease (e.g. ulcerative colitis, Crohn's disease) or toxic megacolon; presence or risk of digestive perforation; ileus or suspicion of symptomatic stenosis or intestinal obstruction; painful abdominal conditions of unknown cause]: permeability to macrogol 4000 may be increased in the presence of intestinal inflammation [19]

How should macrogol 4000 be used in special populations?

Patients who are diabetic or on a galactose-free or low-sodium diet

Women who are pregnant or breastfeeding

Patients with fructose intolerance (rare hereditary disease)

Macrogol 4000 may be used

Macrogol 4000 may be used; consult physician or pharmacist for advice

Use is inadvisable (sorbitol in the orange-grapefruit flavouring undergoes conversion to fructose)

What other special warnings/precautions pertain to the use of macrogol 4000 ?

Allergic reactions (e.g. anaphylactic shock, angioedema, urticaria, rash, pruritus, erythema)

Risk of diarrhoea during treatment

Potential interactions with other medical Macrogol 4000 may possibly cause transient reductions in the absorption of other medicinal prodproducts
If an allergic reaction occurs, stop taking macrogol 4000 and seek medical help immediately

Sulfur dioxide (present in the orange-grapefruit flavouring) may rarely cause severe hypersensitivity reactions and bronchospasm

Consult physician or pharmacist before initiating treatment if the patient has impaired renal or hepatic function, is receiving a diuretic, is elderly or is otherwise prone to electrolyte disturbances (risk of low levels of sodium or potassium in the blood)

Consider monitoring electrolytes in these patients ucts, particularly those with a narrow therapeutic index or a short half-life (e.g. digoxin, antiepileptics, coumarins and immunosuppressive agents), leading to decreased efficacy of these products

\section{Formulation}

Unlike several other HMW macrogol formulations, macrogol 4000 powder for oral solution (i.e. Forlax ${ }^{\circledR}$ formulation) does not contain additional electrolytes, such as sulfate, sodium, potassium and chloride [15]. The addition of electrolytes is not required, as the use of macrogol 4000 is not associated with enteric losses of these electrolytes [14, 20,
23]. As macrogol 4000 does not contain sodium, it may be used by patients on a low-sodium diet. [15]. Moreover, as macrogol 4000 does not contain sucrose, it may be used by patients with diabetes or on a galactose-free diet; however, it should not be taken by patients with fructose intolerance, as it contains sorbitol, which is converted to fructose $[15,16]$.

The Forlax ${ }^{\circledR}$ formulation of macrogol 4000 has an acceptable orange-grapefruit flavour [32-34]. The taste of 
formulations of HMW macrogols without electrolytes may be preferred over that of HMW macrogols + electrolytes. In a study in 100 healthy adults, the taste of macrogol 4000 was preferred over that of a formulation of macrogol $3350+$ electrolytes (mean taste score on a 5-point scale 3.9 vs 2.7 ; $p<0.0001$ ) [32]. In clinical trials, the taste of macrogol 4000 was also preferred over that of macrogol $3350+$ electrolytes $[33,34]$. Children also preferred macrogol 4000 over magnesium hydroxide in two clinical trials $[35,36]$.

\section{What is the efficacy of HMW macrogols in treating constipation?}

The efficacy of HWM macrogols without electrolytes, including macrogol 4000, in the treatment of constipation is well established. Although placebo-controlled trials of macrogol 4000 have not been conducted, there is considerable evidence showing HMW macrogols are more effective than placebo in treating constipation. For example, in randomized, double-blind placebo-controlled trials of macrogol 3350 without electrolytes $\left(\right.$ MiraLax $^{\circledR}$ ) in 100-304 adults [37-40] or children [41], constipation-related outcomes (e.g. successful treatment, stool frequency, consistency and straining, patient/physician assessments of treatment, etc.) improved to a significantly $(p<0.05)$ greater extent with macrogol 3350 than with placebo in the treatment of current constipation [37], occasional constipation [38], chronic constipation [39], medication-induced constipation [40] and childhood constipation [41]. Relative to placebo, significant improvements in constipation-related outcomes were shown within the first few weeks of macrogol 3350 treatment in trials of 1-week to 6-months' duration [37-41], with improvements being maintained with treatment for 6 months [39]. Moreover, in an open-label study in 311 adults (including 117 aged $\geq 65$ years), macrogol 3350 successfully treated chronic constipation in $80-88 \%$ of patients at each monthly timepoint, with durable responses with treatment for up to 12 months [42].

The following subsections focus on the efficacy of macrogol 4000 compared with other treatments for constipation in clinical trials in paediatric and adult patients. The results of randomized, controlled trials of macrogol 4000 in $>60$ patients that are fully published in English are summarized in Tables 2 and 3. Supportive data from meta-analyses and other studies are also provided.

\section{In children}

The efficacy of macrogol 4000 in children was initially shown in studies investigating the use of various dosages of macrogol 4000 in children with chronic functional constipation [43, 44]. A noncomparative 3-month study in 96 children aged $0.5-16$ years found that a daily dosage of $\approx 0.5 / \mathrm{g} / \mathrm{kg}$ was effective in normalizing bowel habits in $>90 \%$ of constipated children and stopping faecal soiling in $>60 \%$ of children with this symptom at baseline [43]. In a 4-week trial in 90 children aged 1-18 years, treatment success [defined as $\geq 3$ bowel movements (BMs)/week with no faecal soiling during week 4] was achieved by $89 \%$ of lowdosage $(0.3 \mathrm{~g} / \mathrm{kg} /$ day $)$ recipients and $97 \%$ of high-dosage $(0.7 \mathrm{~g} / \mathrm{kg} / \mathrm{day})$ recipients; however, the low-dosage was associated with an increased risk of painful defaecation, fewer stools/week and lower parental satisfaction [44].

The 4-g sachet of macrogol 4000 was introduced to meet the clinical need for a macrogol 4000 product suitable for use in young constipated children [45]. This was shown in a retrospective study of macrogol 4000 prescriptions in children aged 0-18 years in France from 1997 to 2007, which found considerable off-label use of the 10-g sachets of macrogol 4000 in children aged $<8$ years before the 2005 introduction of the 4-g sachet for use in children aged 6 months to $<8$ years [45]. Increases in the number of prescriptions for the 4-g sachet increased and those for the 10-g sachet decreased in paediatric patients once the 4-g sachet was available [45], reflecting the clinical need for such a product.

\section{Macrogol 4000 vs macrogol $3350 / 4000$ + electrolytes}

In children, the clinical profile of macrogol 4000 was somewhat better than, or comparable to, that of macrogol $3350+$ electrolytes $[33,46]$. In a 4-week trial, BM frequency was significantly $(p=0.025)$ better with macrogol 4000 than with macrogol 3350 + electrolytes, but there were no significant between-group differences (BGDs) in other constipation-related outcomes (Table 2) [33]. Of note, the macrogol 4000 formulation was better accepted by children than the electrolyte formulation, as shown by the significant $(p<0.001)$ BGDs favouring macrogol 4000 with regard to administration-related difficulties and taste/ palatability, but there was no significant BGD in the rate of compliance.

The non-inferiority of macrogol $3350+$ electrolytes relative to macrogol 4000 was not established in a 52-week trial (Table 2); however, the overall long-term efficacy of the two formulations appeared to be generally comparable [46].

\section{Macrogol 4000 versus lactulose}

In clinical trials in children, macrogol 4000 was generally more effective than lactulose in the treatment of chronic constipation (Table 2) [47-49]. Macrogol 4000 increased the weekly frequency of BMs, stool consistency and other outcomes to a significantly greater extent than lactulose 
within 1 or 2 weeks of treatment in 2- and 4-week trials $[47,48]$. At the end of a 12-week trial in infants and toddlers (Table 2) [49], weekly BM frequency did not differ to a significant extent between macrogol 4000 and lactulose, but stool consistency scores did (Table 2). Changes from baseline in appetite scores (+19 vs $-4 \%)$, and the proportions of patients with faecal impaction ( 2 vs $13 \%$ at week 12) and enema use (17 vs $41 \%$ from week 6 to 12 ) were significantly $(p<0.05)$ better with macrogol 4000 than with lactulose [49].

Macrogol 4000 was also more effective than lactulose in treating chronic neurogenic constipation in children with myelomeningocele [50]. In a 6-month trial in 67 children aged 3-14 years with chronic neurogenic constipation, macrogol 4000 was associated with significantly $(p<0.01)$ higher rates of complete remission of constipation (i.e. $\geq 3$ $\mathrm{BMs} /$ week) than lactulose (46 vs $22 \%$ of patients) and stool frequency (mean 5.1 vs $2.9 \mathrm{BMs} /$ week) at 6 months, as well as at all earlier timepoints ( 1 and 3 months). The frequency of encopresis significantly $(p<0.01)$ decreased from baseline in both groups at month 1 onwards.

In meta-analyses of RCTs in children [51, 52], or primarily children [53], with chronic constipation, macrogols were better than lactulose [51, 53], or lactulose or other non-macrogol laxatives [52], with regard to improvements in weekly BM frequency [51, 53], stool consistency [53], relief of abdominal pain [53], the need to use additional laxative agents [51,53] and successful faecal disimpaction [52] [based on data from six [51], seven [52] or ten RCTs (six in children and four in adults) [53]]

\section{Macrogol 4000 vs magnesium hydroxide}

In children, macrogol 4000 was more or equally effective as magnesium hydroxide (milk of magnesia) in treating chronic functional constipation in two randomized trials [35, 36]. In the larger trial (Table 2) [35], 94 children (aged 1-4 years) received macrogol 4000 at an initial dosage $0.5 \mathrm{~g} / \mathrm{kg} /$ day or magnesium hydroxide at an initial dosage of $0.5 \mathrm{~mL} / \mathrm{kg} / \mathrm{day}$; dosages of both agents could be adjusted to provide the minimum effective dosage. Macrogol 4000 was significantly more effective than magnesium hydroxide with regard to improvements in constipation and patient compliance with treatment (Table 2) [35].

In the smaller trial [36], 38 children received macrogol 4000 or magnesium hydroxide for 6 months. There were no significant BGDs in constipation-related efficacy outcomes, with both treatments providing improvements from baseline in all outcomes. However, macrogol 4000 was more acceptable to children than magnesium hydroxide $(0$ vs $42.9 \%$ of children refused treatment [36].

\section{In adults}

\section{Macrogol 4000 vs macrogol 3350/4000 + electrolytes}

In two 4-week trials (Table 3), macrogol 4000 was effective as PEG 3350 + electrolytes in treating chronic constipation in adults [54], and as effective as PEG 4000+electrolytes in treating elderly institutionalized patients [55]. In the latter trial, the taste of macrogol 4000 tended to more acceptable than that of PEG $3350+$ electrolytes, with 12 and $31 \%$ of macrogol 4000 and PEG 3350 + electrolytes recipients rating the taste to be 'bad' or 'very bad', and 85 and $63 \%$ being willing to continue treatment; however, the BGDs did not achieve statistical significance [55].

In another 4-week trial in 256 adults with chronic constipation, macrogol 4000 was significantly $(p<0.001)$ preferred over macrogol 3350 + electrolytes with regard to patient assessments of global improvement of constipation, evolution in stool frequency, global digestive satisfaction, HR-QOL and taste and physician scores [34]. A network meta-analysis compared the relative efficacy of macrogol $3350 / 4000 \pm$ electrolytes in the treatment of functional constipation in adults [56]. Based on data in a total of 1032 patients, macrogol without electrolytes and macrogol+electrolytes were both effective in increasing weekly stool frequency relative to placebo [increase of 1.8 (95\% CI 1.0-2.8) and 1.9 (95\% CI 0.9-3.0) BMs/week]. However, the addition of electrolytes to HMW macrogols did not appear to improve efficacy, as there were no significant differences between macrogol without and with electrolytes with regard to clinical outcomes based on data in 328 patients [56].

\section{Macrogol 4000 versus lactulose}

In a 3-month tolerability study in 175 adults with chronic constipation [57], patient satisfaction scores were higher with macrogol 4000 than with lactulose (78.8 vs $63.4 \mathrm{~mm}$ ), as was the mean weekly number of stools from week 2 to week 12 (6.1 vs 4.8 at week at 12), and the proportion of patients with reduced defaecation difficulties (69.4 vs 44.5\%) [statistical significance not reported].

In a 6-month tolerability trial [58], macrogol 4000 was significantly more effective than lactulose in improving BM frequency from month 2 onwards in elderly (aged $\geq 70$ years) patients in community- and nursing-home settings with chronic constipation (Table 3). Although $\approx 75 \%$ of patients in both treatment groups achieved normal stool consistency from 2 months onwards, overall stool consistency significantly favoured macrogol 4000 ( $p<0.05$ at each monthly timepoint), with macrogol 4000 being associated with a greater number of patients with soft/liquid stools and a lower number with hard stools than lactulose [58]. 
Table 2 Efficacy of macrogol 4000 without electrolytes in the treatment of chronic functional/idiopathic constipation of randomized, doubleblind trials in $>60$ children published in English

\begin{tabular}{|c|c|c|}
\hline Trial description & Comparators & Key results (macrogol 4000 vs comparator) \\
\hline \multicolumn{3}{|c|}{ Macrogol 4000 vs macrogol $3350+E$ or $4000+E$} \\
\hline $\begin{array}{l}\text { 4-week trial in } 91 \text { children } \\
\text { aged 2-16 years [33] }\end{array}$ & $\begin{array}{l}\text { Macrogol } 4000 \text { vs macrogol } \\
3350+\mathrm{E} \\
\text { (dose based on pt weight, age }^{\text {and/or faecal impaction) }}{ }^{\mathrm{a}}\end{array}$ & $\begin{array}{l}\text { Stool frequency per week (mean) })^{\text {b }} 9.2^{*} \text { vs } 7.8 \text { at week } 4 \\
\text { No. of days with stool during trial (mean): } 22.4^{*} \text { vs } 19.6 \\
\text { No difficulty in administration (\% of pts): } 96^{* *} \text { vs } 62 \\
\text { Compliance }^{\text {c }} \% \text { of pts): } 98^{* * *} \text { vs } 88 \text { at week } 4\end{array}$ \\
\hline $\begin{array}{l}52 \text {-week trial in } 97 \text { children } \\
\text { aged } 0.5-16 \text { years [46] }\end{array}$ & $\begin{array}{l}\text { Macrogol } 4000 \text { vs macrogol } \\
3350+\mathrm{E}(\text { dose based } \\
\text { on pt age) }\end{array}$ & $\begin{array}{l}\text { Total diary constipation sum scores (mean change from BL at week } 52 \text { in } \\
\left.\text { PPP) })^{\mathrm{b}}-3.81 \text { vs }-3.74 \text { (mean BGD }-0.07 ; 95 \% \text { CI }-1.81 \text { to } 1.68\right)^{\mathrm{d}} \\
\text { Daily dosage relative to weight (mean): } 0.43 \text { vs } 0.29^{* * *} \mathrm{~g} / \mathrm{kg} \text { at week } 52 \\
\text { Treatment success }{ }^{\mathrm{e}} \text { (\% of pts): } 33 \text { vs } 25 \text { at week } 1 \\
\text { Treatment success }{ }^{\mathrm{e}} \text { (\% of pts): } 45 \text { vs } 50 \text { at week } 52 \\
\text { Rescue laxative use (\% of pts): } 18 \text { vs } 35 \text { at week } 52 \\
\text { Normal stool consistency (\% of pts): } 70 \text { vs } 52 \text { at week } 4 \\
\text { Treatment duration (days): } 327 \text { vs } 261^{* *}\end{array}$ \\
\hline \multicolumn{3}{|l|}{ Macrogol 4000 vs lactulose } \\
\hline $\begin{array}{l}\text { 2-week trial in } 216 \text { children } \\
\text { aged } 8-18 \text { years [47] }\end{array}$ & $\begin{array}{l}\text { Macrogol } 4000 \text { (20 g/day) } \\
\text { vs lactulose ( } 15 \mathrm{~mL} \text { g/day })\end{array}$ & $\begin{array}{l}\text { Stool frequency per week }{ }^{\mathrm{b}} \text { (median): } 7 * \text { vs } 6 \text { at week } 2 \\
\text { Stool consistency score }{ }^{\mathrm{b}} \text { (mean): } 4.3^{*} \text { vs } 3.6 \text { at week } 2 \\
\text { Clinical remission }{ }^{\mathrm{e}} \text { (\% of pts): } 70.5^{*} \text { vs } 39.6 \text { at week } 1 \\
\text { Clinical remission }{ }^{\mathrm{e}} \text { (\% of pts): } 72.4^{*} \text { vs } 41.4 \text { at week } 2 \\
\text { Disappearance of abdominal pain (\% of pts): } 76.4 \text { vs } 56.7 \text { at week } 2\end{array}$ \\
\hline $\begin{array}{l}\text { 4-week trial in } 88 \text { children } \\
\text { aged } 1-3 \text { years [ } 48]\end{array}$ & $\begin{array}{l}\text { Macrogol } 4000 \text { (10-30 g/day) } \\
\text { vs lactulose (10-30 g/day) }\end{array}$ & $\begin{array}{l}\text { Stool frequency per day }{ }^{\mathrm{b}} \text { (mean change from BL): } 0.51^{* * *} \text { vs } 0.15 \\
\text { at week } 4 \\
\text { Stool consistency score (mean): } 2.1^{* *} \text { vs } 1.7 \text { at week } 4 \\
\text { Ease of stool passage score: } 1.6^{* * *} \text { vs } 1.2 \text { at week } 4\end{array}$ \\
\hline $\begin{array}{l}\text { 12-week trial in } 96 \text { infants/ } \\
\text { toddlers aged } 6 \text { months } \\
\text { to } 3 \text { years [49] }\end{array}$ & $\begin{array}{l}\text { Macrogol } 4000 \text { (4-8 g/day) } \\
\text { vs lactulose (3.33-6.66 g/day) }\end{array}$ & $\begin{array}{l}\text { Stool frequency per week (median): } 8.5 \text { vs } 11.5 \text { (age } 0.5-1 \text { years); } 7 \text { vs } 6 \\
\text { (age }>1-3 \text { years) at week } 12 \\
\text { Frequency of hard stools ( } \% \text { of pts): } 6^{* *} \text { vs } 28 \text { at week } 12 \\
\text { Normal stool consistency ( } \% \text { of pts): } \approx 75 \text { vs } \approx 75 \text { at month } 2-6\end{array}$ \\
\hline \multicolumn{3}{|c|}{ Macrogol 4000 vs magnesium hydroxide } \\
\hline $\begin{array}{l}\text { 4-week trial in } 89 \text { children } \\
\text { aged } 1-4 \text { years [35] }\end{array}$ & $\begin{array}{l}\text { Macrogol } 4000 \text { (median } \\
0.5 \mathrm{~g} / \mathrm{kg} / \text { day) vs magnesium } \\
\text { hydroxide (median } 0.6 \mathrm{~mL} / \mathrm{kg} / \text { day) }\end{array}$ & $\begin{array}{l}\text { Improvement }^{\mathrm{f}}(\% \text { of pts) })^{\mathrm{b}}: 91^{* *} \text { vs } 65 \text { at week } 4 \\
\text { Stool frequency per week (median change from BL): } 3 * \text { vs } 2 \text { at week } 4 \\
\text { Compliance }^{\mathrm{c}} \text { (\% of pts): } 89^{*} \text { vs } 72 \text { at week } 4\end{array}$ \\
\hline
\end{tabular}

Reported pt numbers and results are in the intent-to-treat population unless otherwise stated

$B L$ baseline, $E$ electrolytes, $P P P$ per-protocol population, $p t(s)$ patient(s)

${ }^{*} p<0.05, * * p<0.01, * * * p \leq 0.001$ vs comparator

${ }^{a}$ In children without faecal impaction: macrogol 4000 dosage was $0.7 \mathrm{~g} / \mathrm{kg} /$ day in two divided doses (maximum $30 \mathrm{~g} / \mathrm{day}$ ); macrogol $3350+\mathrm{E}$ dosage was one, two or four 6.9-g sachets based on age. In children with faecal impaction: macrogol 4000 dosage was $1.5 / \mathrm{g} / \mathrm{kg}$ in $2 \mathrm{divided}$ doses until resolution or for 6 days; macrogol $3350+\mathrm{E}$ dosage was given as an initial dose of four 6.9-g sachets, which was increased by two sachets/day (maximum twelve sachets/day) until resolution or for 7 days

${ }^{\mathrm{b}}$ Primary/co-primary endpoint (no primary clinical endpoint in the trial primarily assessing tolerance [49])

${ }^{\mathrm{c}}$ Defined at $>80 \%$ of scheduled doses of the medication being received by the $\mathrm{pt}$

${ }^{\mathrm{d}}$ Non-inferiority criteria for macrogol $4000+\mathrm{E}$ vs macrogol 4000 without $\mathrm{E}$ was not met (95\% CI for BGD is not $\leq 1.5$ )

${ }^{\text {e}}$ Defined as $>3 \mathrm{BMs} /$ week + either $<1$ episode of faecal incontinence [46] or normalized stool consistency [47]

${ }^{\mathrm{f}}$ Defined as the $\%$ of pts with $\geq 3 \mathrm{BMs} /$ week, $\leq 2$ episodes of faecal incontinence/month and no painful defaecation \pm laxative therapy

In the network analysis [56], there was a $97.6 \%$ probability that macrogol was better in increasing the frequency of BMs relative to lactulose in adults with chronic constipation (based on one dataset) [28]. In meta-analyses in adults with chronic constipation [56, 59], macrogols were better than lactulose [56, 59], with regard to improvements in weekly BM frequency [56], (based on data from seven RCTs [59]). 
Table 3 Efficacy of macrogol 4000 without electrolytes in the treatment of chronic functional/idiopathic constipation in randomized, doubleblind trials in $>60$ adults published in English

\begin{tabular}{|c|c|c|}
\hline $\begin{array}{l}\text { Trial description (no. of ITT } \\
\text { pts) }\end{array}$ & Comparators & Key results (macrogol 4000 vs comparator) \\
\hline \multicolumn{3}{|c|}{ Macrogol 4000 vs macrogol $3350+E$ or $4000+E$ in adults or the elderly } \\
\hline \multirow[t]{2}{*}{ 4-week trial in 266 adults [54] } & $\begin{array}{l}\text { Standard dose: macrogol } 4000 \\
(10 \mathrm{~g} / \text { day }) \text { vs macrogol } \\
3350+\mathrm{E}(5.9 \mathrm{~g} / \text { day })\end{array}$ & $\begin{array}{l}\text { Stool frequency per week (mean) })^{\mathrm{a}}: 6.2^{\dagger} \text { vs } 7.2^{\dagger} \text { at week } 4^{\mathrm{b}} \\
\text { Stool consistency score (mean): } 3.4^{\dagger} \text { vs } 3.7^{\dagger} \text { at week } 4^{\mathrm{b}} \\
\text { Straining at stool score (mean): } 2.0^{\dagger} \text { vs } 1.9^{\dagger} \text { at week } 4^{\mathrm{b}} \\
\text { First BM within } 1 \text { day of starting treatment: (\% of pts): } 67.3 \text { vs } 77.1^{\mathrm{b}}\end{array}$ \\
\hline & $\begin{array}{l}\text { High dose: macrogol } 4000 \\
(20 \text { g/day }) \text { vs macrogol } \\
3350+\mathrm{E}(11.8 \mathrm{~g} / \text { day })\end{array}$ & $\begin{array}{l}\text { Stool frequency per week (mean) })^{\mathrm{a}}: 7.2^{\dagger} \text { vs } 7.8^{\dagger} \text { at week } 4^{\mathrm{b}} \\
\text { Stool consistency score (mean): } 3.2^{\dagger} \text { vs } 3.1^{\dagger} \text { at week } 4^{\mathrm{b}} \\
\text { Straining at stool score (mean): } 2.0^{\dagger} \text { vs } 2.0^{\dagger} \text { at week } 4^{\mathrm{b}} \\
\text { First BM within } 1 \text { day of starting treatment: (\% of pts): } 73.1 \text { vs } 82.3^{\mathrm{b}}\end{array}$ \\
\hline $\begin{array}{l}4 \text {-week trial in } 62 \text { institutional- } \\
\text { ized pts aged } \geq 65 \text { years }[55]\end{array}$ & $\begin{array}{l}\text { Macrogol } 4000 \text { vs macrogol } \\
4000+E(12 \text { g daily } \\
\text { or every other day) }\end{array}$ & $\begin{array}{l}\text { Stool frequency per week (mean) })^{\mathrm{a}}: 8.5 \text { vs } 8.4 \text { at week } 4 \\
\text { Normal stool consistency (\% of pts):70 vs } 52 \text { at week } 4\end{array}$ \\
\hline \multicolumn{3}{|c|}{ Macrogol 4000 vs lactulosein the elderly } \\
\hline $\begin{array}{l}\text { 6-month trial in } 245 \mathrm{pts} \\
\text { aged } \geq 70 \text { years }[58]\end{array}$ & $\begin{array}{l}\text { Macrogol } 4000 \text { (10-30 g/day) vs } \\
\text { lactulose (10-30 g/day) }\end{array}$ & $\begin{array}{l}\text { Stool frequency per week (mean): } 7.0-7.3^{*} \text { vs } 5.5-6.2 \text { at month } 2-6 \\
\text { Normal stool consistency }(\% \text { of pts) } \approx 75 \mathrm{vs} \approx 75 \text { at month } 2-6\end{array}$ \\
\hline
\end{tabular}

Reported pt numbers and results are in the intent-to-treat population

$E$ electrolytes, $p t(s)$ patient(s)

$* p<0.05$ vs comparator; ${ }^{\dagger} p<0.001$ vs baseline

${ }^{a}$ Primary endpoint (no primary clinical endpoint in the trial primarily assessing tolerance [58])

${ }^{b}$ No significant between-treatment difference

Macrogol 4000 was predicted to be cost effective relative to lactulose from a UK healthcare perspective in adults aged $\geq 18$ years with chronic functional constipation [60]. A decision model was used to estimate the cost-effectiveness of general practitioners prescribing macrogol 4000 instead of lactulose over 3 months (year of costing not reported). At 3 months after laxative initiation, 42 and $31 \%$ of macrogol 4000 and lactulose recipients were predicted to be successfully treated $(p<0.0001)$, at a respective cost of $\$ 115$ and $£ 102$, and with respective increases of 0.213 and 0.210 quality-adjusted life-years (QALYs). This equated to an acceptable cost per QALY gained of $\$ 4333$ [60].

\section{Macrogol 4000 vs psyllium hydrocolloid}

Macrogol 4000 and psyllium hydrocolloid were both effective in treating chronic constipation in a 2-week trial in 124 adults (available as an abstract) [61]. Once-daily administration of $10 \mathrm{~g}$ of macrogol 4000 provided significantly $(p<0.05)$ higher rates of effectiveness (not defined) than twice-daily administration of psyllium hydrocolloid $6 \mathrm{~g}(81.0$ vs $62.7 \%$ ). BM frequency and stool consistency were normalized and main GI symptoms disappeared in both treatment groups [61].

\section{What is the tolerability profile of macrogol 4000?}

Macrogol 4000 was very well-tolerated in clinical trials in infants/pre-school children [35, 48, 49], older children [27, $33,36,43,44,46,47]$, adults $[34,54,56,57,62]$ and the elderly $[55,58]$.

In 147 children aged $0.5-15$ years in clinical trials and post-marketing reports, most treatment-emergent adverse events (TEAEs) were minor, transient and primarily involved the GI system. The only common TEAEs (i.e. those reported in $\geq 1$ to $<10 \%$ of children) were abdominal pain and diarrhoea (which may cause perianal soreness) and uncommon TEAEs (i.e. reported in $\geq 0.1$ to $<1 \%$ of children) include vomiting, abdominal distension and nausea. In adults, additional uncommon TEAEs include urgency to defaecate and faecal incontinence [15].

\section{Macrogol 4000 vs macrogol 3350/4000 + electrolytes}

Macrogol 4000 has a tolerability profile that was somewhat better than, or similar to, that of macrogol $3350+$ electrolytes [33, 46, 54] or macrogol $4000+$ electrolytes [55]. The network meta-analysis found no difference between macrogol \pm electrolytes with regard to safety or tolerability [56]. 
In children, macrogol 4000 was associated with a significantly lower proportions of patients with 1-2 episodes of nausea than macrogol 3350 + electrolytes (2 vs $21 \%$; $p=0.003$ ) in a 4-week trial [33]; however, there were no significant BGDs in the tolerability of these laxatives in the 1-year trial in children [46].

The tolerability profile of macrogol 4000 was similar to that with macrogol 33500 + electrolytes (with an increased frequency of diarrhoea at maximum doses of both) in adults [54], and to that with macrogol $4000+$ electrolytes in elderly patients (with the exception of significantly lower plasma sodium levels with macrogol 4000; 137.7 vs 138.9 mmol/L; $p=0.012$ ) [55].

\section{Macrogol 4000 vs lactulose}

The overall tolerability profile of longer-term treatment with macrogol 4000 is comparable to that with lactulose $[49,57,58]$. In infants and toddlers, the biological tolerance of macrogol 4000 did not differ from that of lactulose, with no BGDs in changes from baseline in whole blood parameters, vitamin A levels and iron levels after 3 months of treatment [49]. With regards to clinical tolerance over 3 months, the median rate of new onset/worsened vomiting was significantly lower with macrogol 4000 than with lactulose ( 1 vs 2 episodes; $p<0.05$ ), as was the median duration of new onset/worsened flatulence (3 vs 5 days; $p=0.005)$; there were no other BGDs in other digestive adverse effects [49]. No significant adverse effects [47, 48] or laboratory abnormalities [47] were observed during 2 [47] or 4 weeks [48] of treatment with either macrogol 4000 or lactulose in children aged 1-3 [48] or $>8$ years [47].

A 3-month randomized study in 175 adults with chronic constipation evaluated the tolerability of macrogol 4000 versus that of lactulose (initial dosages of both adjusted based on response) [57]. There were no significant BGDs with regard to global clinical tolerance (as evaluated by the investigator), general clinical tolerance (weight, heart rate, systolic and diastolic blood pressure), biological tolerance (haematological, metabolic, renal, hepatic, and malabsorption laboratory values), GI symptoms [with the exception of bloating, which improved to a significantly $(p<0.05)$ greater extent with macrogol 4000], and local tolerance (evaluated by sigmoidoscopy and histopathological examination of biopsies) [57]. Likewise, in the tolerability trial in elderly patients [58], there were no clinically relevant changes in biochemical and nutritional parameters over the 6-months, and no significant differences between macrogol 4000 and lactulose with regard to tolerability outcomes.

\section{Other studies}

Both macrogol 4000 and magnesium hydroxide were welltolerated in trials in children $[35,36]$, with macrogol 4000 having a lower rate of diarrhoea than magnesium hydroxide in one trial (4.3 vs $28 \%$ of patients; $p=0.002$ ) [35].

Long-term treatment with macrogol 4000 was also welltolerated in open-label trials in children [27] or adults [62] with chronic constipation. Treatment with macrogol 4000 for a mean of 17 months (range 7-46 months) was not associated with significant clinical problems in 100 children aged 2-18 years [27]. Although hyperphosphataemia occurred in 11 children, it resolved spontaneously without treatment discontinuation in all but one child. Macrogol 4000 was not associated with elevated AST levels [27].

Likewise, in 16 adults receiving macrogol 4000 for a mean of 17.3 months (range 3-29), global tolerance was excellent, with no signs of malabsorption [62].

\section{Risk of anaphylaxis}

Cases of anaphylaxis following the use of HMW macrogols have been reported, with most being related to their use as lavage solutions for bowel preparation [63-66]. The Allergy Vigilance Network recorded five cases of severe macrogolrelated anaphylaxis from 2010 to 2012, including two cases with macrogol 4000 (one presenting as generalized urticaria following treatment with $10 \mathrm{~g}$, and one as anaphylactic shock following treatment with $20 \mathrm{~g}$ ) [64]. Appropriate measures (Table 1) should be taken if anaphylaxis occurs.

\section{What is the current clinical position of macrogol 4000?}

Macrogol 4000, a biologically inert, non-absorbable osmotic laxative, is a valuable and well-tolerated option in the treatment of chronic constipation. According to recent UK National Institute for Health and Care Excellent (NICE) [8] and North American Society for Pediatric Gastroenterology, Hepatology, and Nutrition and the European Society for Pediatric Gastroenterology, Hepatology, and Nutrition (ESPGHAN/NASPGHAN) [9] guidelines, HMW macrogols, such as macrogol 4000, are indicated as first-line pharmacological treatments for chronic constipation in children and young people. Likewise, according to guidelines from the American College of Gastroenterology (ACG) [10], the American Society of Colon and Rectal Surgeons (ASCRS) [\#8] and the Societe Nationale Francaise de Colo-Proctologie (SNFCP) [11], HMW macrogols are indicated as firstline pharmacological treatments for chronic constipation in adults. Such recommendations are based on the excellent 
short- and long-term efficacy and tolerability profiles of HMW macrogols, including macrogol 4000.

HMW macrogols \pm electrolytes have generally similar efficacy profiles. However, the taste of macrogol 4000 is generally preferred over that of macrogol $3350+$ electrolytes, which is probably due to the taste of the added electrolytes. This may help improve patient compliance, especially in children and the elderly, which, in turn, will improve the effectiveness of treatment for chronic constipation. The addition of electrolytes to macrogol 4000 is not required as it is not associated with clinically relevant electrolyte disturbances.

Macrogol 4000 is more effective than lactulose in increasing BM frequency and improving stool consistency and other constipation-related outcomes, and is associated with less vomiting and flatulence as, unlike lactulose, HMW macrogols are not fermented by colonic bacteria. Whereas HMW macrogols are indicated for the first-line treatment of chronic constipation in children, lactulose is indicated as secondline therapy in children if HWM macrogols are not tolerated (NICE guidelines) [8] or as first-line therapy if HWM macrogols are not available (ESPGHAN/NASPGHAN guidelines) [9]. In adults, the use of HMW macrogols is preferred over that of lactulose, according to the ASCRS [12] and SNFCP [11] guidelines, with the ACG guidelines stating that the quality of evidence of effectiveness is high for HMW macrogols but low for lactulose [\#13]. Comparisons with other osmotic and bulk-forming laxatives are limited, with macrogol 4000 being at least or more effective in treating chronic constipation than magnesium hydroxide in children and psyllium hydrocolloid in adults. Prucalopride, a selective, high affinity serotonin $\left(5-\mathrm{HT}_{4}\right)$ receptor agonist with prokinetic activity, is another effective option for the treatment of chronic constipation; however, it is only currently approved to treat symptoms of chronic constipation in adults in whom laxatives fail to provide adequate relief in the EU [67], and is not approved in the USA. According to the SNFCP guidelines [11], the use of prucalopride is indicated after the failure of osmotic laxatives and lifestyle and dietary changes.

The use of HMW macrogols as a preferred laxative has been shown in a 2-month multicentre study in 878 adults with chronic constipation conducted in Italy [68]. HMW macrogols were prescribed to $69.4 \%$ of patients, enemas to $27.1 \%$, suppositories/microenemas to $22.6 \%$, prucalopride to $14.4 \%$, lactulose/lactitole to $6.6 \%$, and stimulant, softening and saline laxatives to $6.3,5.2$ and $3.5 \%$ of patients, respectively. In addition, $82.2 \%$ of patients received lifestyle recommendations, $85.3 \%$ dietary suggestions, $55.7 \%$ fibre supplements and $36.2 \%$ probiotics [68].

Further pharmacoeconomic studies versus new laxative agents would be useful. In their absence, acquisition costs for HMW macrogols may be lower than that of new agents, and macrogol 4000 has been predicted to be cost effective relative to lactulose from a UK healthcare perspective [60].
Acknowledgements The manuscript was reviewed by: $M$. Alboraie, Department of Internal Medicine, Al-Azhar University, Cairo, Egypt; M. Bellini, Gastroenterology Unit, University of Pisa, Pisa, Italy; M.A. Benninga, Department of Pediatric Gastroenterology and Nutrition, Emma Children's Hospital/Academic Medical Center, Amsterdam, the Netherlands; C. Blandizzi, Department of Clinical and Experimental Medicine, University of Pisa, Pisa, Italy. During the peer review process, Ipsen Consumer Healthcare, a marketing-authorization holder of macrogol 4000, was also offered an opportunity to provide a scientific accuracy review of their data. Changes resulting from comments received were made on the basis of scientific and editorial merit.

\section{Compliance with ethical standards}

Funding The preparation of this review was not supported by any external funding.

Conflicts of interest K. A. Lyseng-Williamson is an employee of Adis/ Springer, is responsible for the article content and declares no conflicts of interest.

Open Access This article is distributed under the terms of the Creative Commons Attribution-NonCommercial 4.0 International License (http://creativecommons.org/licenses/by-nc/4.0/), which permits any noncommercial use, duplication, adaptation, distribution and reproduction in any medium or format, as long as you give appropriate credit to the original author(s) and the source, provide a link to the Creative Commons license and indicate if changes were made.

\section{References}

1. Suares NC, Ford AC. Prevalence of, and risk factors for, chronic idiopathic constipation in the community: systematic review and meta-analysis. Am J Gastroenterol. 2011;106(9):1582-91.

2. Tamura A, Tomita T, Oshima T, et al. Prevalence and self-recognition of chronic constipation: results of an internet survey. $\mathrm{J}$ Neurogastroenterol Motil. 2016;22(4):677-85.

3. Shafe AC, Lee S, Dalrymple JS, et al. The LUCK study: laxative usage in patients with GP-diagnosed constipation in the UK, within the general population and in pregnancy. An epidemiological study using the General Practice Research Database (GPRD). Ther Adv Gastroenterol. 2011;4(6):343-63.

4. Lindberg G, Hamid S, Malfertheiner P, et al. Constipation: a global perspective. Milwaukee: World Gastroenterology Organisation; 2010.

5. Koppen IJN, Vriesman MH, Saps M, et al. Prevalence of functional defecation disorders in children: a systematic review and meta-analysis. J Pediatr. https://doi.org/10.1016/j.jpeds.2018.02.029 (Epub 2018).

6. Johanson JF, Kralstein J. Chronic constipation: a survey of the patient perspective. Aliment Pharmacol Ther. 2007;25(5):599-608.

7. Wald A, Sigurdsson L. Quality of life in children and adults with constipation. Best Pract Res Clin Gastroenterol. 2011;25(1):19-27.

8. National Institute for Health and Care Excellence (NICE). Clinical management of idiopathic constipation in children and young people. Manchester: NICE; 2015.

9. Tabbers MM, DiLorenzo C, Berger MY, et al. Evaluation and treatment of functional constipation in infants and children: evidence-based recommendations from ESPGHAN and NASPGHAN. J Pediatr Gastroenterol Nutr. 2014;58(2):258-74.

10. Ford AC, Moayyedi P, Lacy BE, et al. American College of Gastroenterology monograph on the management of irritable bowel 
syndrome and chronic idiopathic constipation. Am J Gastroenterol. 2014;109(Suppl 1):S2-26.

11. Vitton V, Damon H, Siproudhis L. Societe Nationale Francaise de Colo-Proctologie (SNFCP). Recommendations for the management of constipation in clinical practice: 2016 [in French]. Paris: SNFCP; 2016. p. 2016.

12. Paquette IM, Varma M, Ternent C, et al. The American Society of Colon and Rectal Surgeons' clinical practice guideline for the evaluation and management of constipation. Dis Colon Rectum. 2016;59(6):479-92.

13. Koppen IJN, Broekaert IJ, Wilschanski M, et al. Role of polyethylene glycol in the treatment of functional constipation in children. J Pediatr Gastroenterol Nutr. 2017;65(4):361-3.

14. Fordtran JS, Hofmann AF. Seventy years of polyethylene glycols in gastroenterology: the journey of PEG 4000 and 3350 from nonabsorbable marker to colonoscopy preparation to osmotic laxative. Gastroenterology. 2017;152(4):675-80.

15. Forlax ${ }^{\circledR} 4 \mathrm{~g}$, powder for oral solution in sachet: summary of product characteristics. Boulogne-Billancourt: Ipsen Pharma; 2015.

16. Forlax ${ }^{\circledR} 10 \mathrm{mg}$ (macrogol 4000), powder for oral solution in sachet: patient information leaflet. Slough: Ipsen Ltd; 2016.

17. Schiller LR, Emmett M, Santa Ana CA, et al. Osmotic effects of polyethylene glycol. Gastroenterology. 1988;94(4):933-41.

18. Winne D, Gorig H. Appearance of ${ }^{14} \mathrm{C}$-polyethylene glycol 4000 in intestinal venous blood: influence of osmolarity and laxatives, effect on net water flux determination. Naunyn Schmiedebergs Arch Pharmacol. 1982;321(2):149-56.

19. Seidman EG, Hanson DG, Walker WA. Increased permeability to polyethylene glycol 4000 in rabbits with experimental colitis. Gastroenterology. 1986;90(1):120-6.

20. Hammer HF, Santa Ana CA, Schiller LR, et al. Studies of osmotic diarrhea induced in normal subjects by ingestion of polyethylene glycol and lactulose. J Clin Invest. 1989;84(4):1056-62.

21. Fritz E, Hammer HF, Lipp RW, et al. Effects of lactulose and polyethylene glycol on colonic transit. Aliment Pharmacol Ther. 2005;21(3):259-68.

22. Herve $\mathrm{S}$, Leroi AM, Mathiex-Fortunet $\mathrm{H}$, et al. Effects of polyethylene glycol 4000 on 24-h manometric recordings of left colonic motor activity. Eur J Gastroenterol Hepatol. 2001;13(6):647-54.

23. Hudziak H, Bronowicki JP, Franck P, et al. Low-dose polyethylene glycol 4000: digestive effects. Randomized double-blind study in healthy subjects. Gastroenterol Clin Biol. 1996;20(5):418-23.

24. Bernier JJ, Donazzolo Y. Effect of low-dose polyethylene glycol 4000 on fecal consistency and dilution water in healthy subjects [in French]. Gastroenterol Clin Biol. 1997;21(1):7-11.

25. Klauser AG, Muhldorfer BE, Voderholzer WA, et al. Polyethylene glycol 4000 for slow transit constipation. Z Gastroenterol. 1995;33(1):5-8.

26. Mangin I, Bouhnik Y, Suau A, et al. Molecular analysis of intestinal microbiota composition to evaluate the effect of PEG and lactulose laxatives in humans. Microb Ecol Health Dis. 2002;14(1):54-62.

27. Bae SH. Long-term safety of PEG 4000 in children with chronic functional constipation: a biochemical perspective. Korean J Pediatr. 2010;53(7):741-4.

28. Bouhnik Y, Neut C, Raskine L, et al. Prospective, randomized, parallel-group trial to evaluate the effects of lactulose and polyethylene glycol-4000 on colonic flora in chronic idiopathic constipation. Aliment Pharmacol Ther. 2004;19(8):889-99.

29. Williams KC, Rogers LK, Hill I, et al. PEG 3350 administration is not associated with sustained elevation of glycol levels. J Pediatr. 2018;195:148-53.

30. Pelham RW, Nix LC, Chavira RE, et al. Clinical trial: single- and multiple-dose pharmacokinetics of polyethylene glycol (PEG-3350) in healthy young and elderly subjects. Aliment Pharmacol Ther. 2008;28(2):256-65.
31. Ragueneau I, Poirier JM, Radembino N, et al. Pharmacokinetic and pharmacodynamic drug interactions between digoxin and macrogol 4000, a laxative polymer, in healthy volunteers. Br J Clin Pharmacol. 1999;48(3):453-6.

32. Szojda MM, Mulder CJ, Felt-Bersma RJ. Differences in taste between two polyethylene glycol preparations. J Gastrointest Liver Dis. 2007;16(4):379-81.

33. Savino F, Viola S, Erasmo M, et al. Efficacy and tolerability of PEG-only laxative on faecal impaction and chronic constipation in children: a controlled double blind randomized study vs a standard PEG-electrolyte laxative. BMC Pediatr. 2012;12:178.

34. Couturier D. Comparative study of Forlax and Transipeg in the treatment of functional constipation in the adult [in French]. Ann Gastroenterol Hepatol (Paris). 1996;32(3):135-40.

35. Ratananomgkol R, Lertmaharit $\mathrm{S}$, Jongpiputvanich $\mathrm{S}$. Polyethylene glycol 4000 without electrolytes versus milk of magnesia for the treatment of functional constipation in infants and young children: a randomized controlled trial. Asian Biomed. 2009;3(4):391-9.

36. Gomes PB, Duarte MA, Melo Mdo C. Comparison of the effectiveness of polyethylene glycol 4000 without electrolytes and magnesium hydroxide in the treatment of chronic functional constipation in children [in Portuguese]. J Pediatr (Rio J). 2011;87(1):24-8.

37. DiPalma JA, DeRidder PH, Orlando RC, et al. A randomized, placebo-controlled, multicenter study of the safety and efficacy of a new polyethylene glycol laxative. Am J Gastroenterol. 2000;95(2):446-50.

38. McGraw T. Polyethylene glycol 3350 in occasional constipation: a one-week, randomized, placebo-controlled, double-blind trial. World J Gastrointest Pharmacol Ther. 2016;7(2):274-82.

39. Dipalma JA, Cleveland MV, McGowan J, et al. A randomized, multicenter, placebo-controlled trial of polyethylene glycol laxative for chronic treatment of chronic constipation. Am J Gastroenterol. 2007;102(7):1436-41.

40. DiPalma JA, Cleveland MB, McGowan J, et al. A comparison of polyethylene glycol laxative and placebo for relief of constipation from constipating medications. South Med J. 2007;100(11):1085-90.

41. Nurko S, Youssef NN, Sabri M, et al. PEG3350 in the treatment of childhood constipation: a multicenter, double-blinded, placebocontrolled trial. J Pediatr. 2008;153(2):254-61.

42. Di Palma JA, Cleveland MV, McGowan J, et al. An open-label study of chronic polyethylene glycol laxative use in chronic constipation. Aliment Pharmacol Ther. 2007;25(6):703-8.

43. Dupont C, Leluyer B, Amar F, et al. A dose determination study of polyethylene glycol 4000 in constipated children: factors influencing the maintenance dose. J Pediatr Gastroenterol Nutr. 2006;42(2):178-85.

44. Dziechciarz P, Horvath A, Szajewska H. Polyethylene glycol 4000 for treatment of functional constipation in children. J Pediatr Gastroenterol Nutr. 2015;60(1):65-8.

45. Qizilbash N, Mendez I. Trends in utilization and off-label use of polyethylene glycol 4000 laxatives and the prevalence of constipation in children in France. Clin Exp Gastroenterol. 2011;4:181-8.

46. Bekkali NLJ, Hoekman DR, Leim O, et al. Polyethylene glycol 3350 with electrolytes versus polyethylene glycol 4000 for constipation: a randomized, controlled trial. J Pediatr Gastroenterol Nutr. 2018;66(1):10-5.

47. Wang Y, Wang B, Jiang X, et al. Polyethylene glycol 4000 treatment for children with constipation: a randomized comparative multicenter study. Exp Ther Med. 2012;3(5):853-6.

48. Treepongkaruna S, Simakachorn N, Pienvichit P, et al. A randomised, double-blind study of polyethylene glycol 4000 and lactulose in the treatment of constipation in children. BMC Pediatr. 2014;14:153. https://doi.org/10.1186/471-2431-14-153.

49. Dupont C, Leluyer B, Maamri N, et al. Double-blind randomized evaluation of clinical and biological tolerance of polyethylene glycol 4000 versus lactulose in constipated children. J Pediatr Gastroenterol Nutr. 2005;41(5):625-33. 
50. Rendeli C, Ausili E, Tabacco F, et al. Polyethylene glycol 4000 vs. lactulose for the treatment of neurogenic constipation in myelomeningocele children: a randomized-controlled clinical trial. Aliment Pharmacol Ther. 2006;23(8):1259-65.

51. Gordon M, MacDonald JK, Parker CE, et al. Osmotic and stimulant laxatives for the management of childhood constipation. Cochrane Database Syst Rev. 2016;(8):Cd009118.

52. Chen SL, Cai SR, Deng L, et al. Efficacy and complications of polyethylene glycols for treatment of constipation in children: a meta-analysis. Medicine (Baltimore). 2014;93(16):e65. https://doi. org/10.1097/MD.0000000000000065.

53. Lee-Robichaud $\mathrm{H}$, Thomas $\mathrm{K}$, Morgan J, et al. Lactulose versus polyethylene glycol for chronic constipation. Cochrane Database Syst Rev. 2010;(7):Cd007570.

54. Chaussade S, Minic M. Comparison of efficacy and safety of two doses of two different polyethylene glycol-based laxatives in the treatment of constipation. Aliment Pharmacol Ther. 2003;17(1):165-72.

55. Seinela L, Sairanen U, Laine T, et al. Comparison of polyethylene glycol with and without electrolytes in the treatment of constipation in elderly institutionalized patients: a randomized, double-blind, parallel-group study. Drugs Aging. 2009;26(8):703-13.

56. Katelaris P, Naganathan V, Liu K, et al. Comparison of the effectiveness of polyethylene glycol with and without electrolytes in constipation: a systematic review and network meta-analysis. BMC Gastroenterol. 2016;16:42. https://doi.org/10.1186/s12876-016-0457-9.

57. Denis P, Teillet L, Moulias R. Long-term tolerance of Forlax ${ }^{\circledR}$ : a comparative study versus lactulose in patients with functional constipation [in French]. Gastroenterologie. 1997.

58. Chassagne P, Ducrotte P, Garnier P, et al. Tolerance and and longterm efficacy of polyethylene glycol 4000 Forlax compared to lactulose in elderly patients with chronic constipation. J Nutr Health Aging. 2017;21(4):429-39.

59. Belsey JD, Geraint M, Dixon TA. Systematic review and meta analysis: polyethylene glycol in adults with non-organic constipation. Int J Clin Pract. 2010;64(7):944-55.

60. Guest JF, Clegg JP, Helter MT. Cost-effectiveness of macrogol 4000 compared to lactulose in the treatment of chronic functional constipation in the UK. Curr Med Res Opin. 2008;24(7):1841-52.

61. Zhou L, Xia Z, Lin S, et al. A randomized controlled multicenter clinical trial on the treatment of chronic functional constipation with PEG4000. Chin J Clin Pharmacol. 2001;1:7-10.

62. Denis P, Lerebours E. Study of the long-term tolerance of Forlax ${ }^{\circledR}$ in 16 patients treated for an average of 17 months for chronic constipation [in French]. Med Chir Digest. 1996;25(5):1-4.

63. Anton Girones M, Roan Roan J, de la $\mathrm{Hoz} \mathrm{B}$, et al. Immediate allergic reactions by polyethylene glycol 4000: two cases. Allergol Immunopathol (Madr). 2008;36(2):110-2.

64. Nguyen VM, Petitpain N, Lovato B, et al. Anaphylaxis to macrogol: five cases reported to the Allergy Vigilance Network [in French]. Rev Fr Allergol. 2014;54(4):307-10.

65. Pizzimenti S, Heffler E, Gentilcore E, et al. Macrogol hypersensitivity reactions during cleansing preparation for colon endoscopy. $\mathrm{J}$ Allergy Clin Immunol Pract. 2014;2(3):353-4.

66. Savitz JA, Durning SJ. A rare case of anaphylaxis to bowel prep: a case report and review of the literature. Mil Med. 2011;176(8):944-5.

67. Resolor (prucalopride) tablets: summary of product characteristics. London: European Medicines Agency; 2018.

68. Bellini M, Usai-Satta P, Bove A, et al. Chronic constipation diagnosis and treatment evaluation: the "CHRO.CO.DI.T.E." study. BMC Gastroenterol. 2017;17(1):11. https://doi.org/10.1186/s12876-016-0556-7. 